\title{
Does the literature deserve the name?
}

The general opinion that the scientific literature does not deserve the name is widely accepted, but those chiefly responsible, the authors of research reports, seem unable to change their ways.

Most scientific writing is narrative, essentially the stuff with which Joseph Conrad won fame and fortune a century ago. A person wishing to describe the outcome of a series of experiments, or of observations, and to suggest what they signify, has also to tell a tale. But the task is necessarily simpler than those that Conrad chose to face. Imagination, or too much of it, is neither necessary nor permissible (for obvious reasons). And the authors or research reports are not required to strive for dramatic endings. Indeed, they would be out of place. So why is the narrative or research so often laboured and, more mystifying and even more important, so difficult to understand?

A frequent defence is that the scientific literature is so stylized that authors' narrative talents are inhibited by the straitjackets into which they are forced, but this can hardly be the case. It is true that some journals demand that research should be described under various headings, METHODS, METHODS AND MATERIALS, CONCLUSIONS and - of fine distinction - DISCUSSION, but that should make the task of telling a simple tale easier, not more difficult. If the structure of the narrative is predetermined, should not its elements be more easily told in simple language?

What seems to happen, instead, is that a pre-determined format is taken as an instruction (or an excuse) for replacing narrative prose with a listing. Sentences without verbs become commonplace. Abbreviations, not simply for commonly used reagents, but for materials first defined elsewhere in the same article, are liberally sprinkled among the intelligible words. The assumption seems to be that people will not wish to read these stylized sections of a research report as if they were pieces of the narrative, but will refer to them only in the quest for information on, say, the conduct of an experiment.

For what it is worth, many of the legends accompanying figures in this journal are not very different, although we take some care to provide each sentence with a verb if the author has overlooked the need for one. Omissions that cannot as easily be remedied are of the phrases that would help readers quickly grasp why some experimental procedure has been followed. All too often, for example, people will say merely that they have incubated some system $Q$ "in the presence" of a radioactive material without adding some qualifying phrase such as Q "to label the product".

"But people in the field will know what is going on, and the others will not care", is the customary defence. But can that be certain? While those familiar with experiments of the kind described may indeed be able to understand what is going on, will not even they benefit by being able to read more quickly from explicit pointers? And might there be some merit in capturing the interest of people working in quite different fields? With that said, of course, the now-familiar phrase "Quantification was achieved by ..." deserves to be banned.

The cramping consequences of the stylized nature of some communications are probably exaggerated by those who mistake a listing for literature, but that is not the reason most commonly given to explain the obscurity of the literature, nor should it carry much weight with hapless readers that authors often say that space is at a premium, and that the demands of journals require of them feats of compression surpassed only by the better poets. The truth is that most editors would willingly give extra space to well-written articles, that the avoidance of repetition by the judicious use of pronouns would usually save more space than is consumed by phrases meant to say what experimental steps are for, and that the most common thief of space is the narrative of material only peripherally relevant to the purpose of an article.

Much the most common defence of the obscurity of the literature is that it is intrinsically obscure, but that is at best only half an excuse. Of course, the literature is by definition full of articles that describe previously unknown phenomena, or which embody data whose significance has not yet been fully appreciated. It is also well-known, among narrative writers, that it is easier to tell a clear tale than one whose purpose is unclear. So should it not be the rule, rather than the exception, that scientific articles are clouded?

Only if one accepts that it is not possible to make clear statements about circumstances that are themselves uncertain. But that is plainly not the case. Even if a person has discovered something truly puzzling - perhaps, to take a classic case, that the bombardment of uranium with neutrons yields short-lived $\beta$ activity as well as $\alpha$ activity - there should be no difficulty is saying that "there is at present no explanation of these observations, which are nevertheless easily distinguishable from the background noise and also reproducible". (That is more or less what Fermi said about his experiments with uranium; it remains a puzzle, and a surprise, that he missed the explanation.)

The truth is that badly written papers are most often written by people who are not clear in their own minds what they want to say, and which seem also to derive some of their obscurity from extraneous but important issues that complicate the tale an author has to tell. If, for example, a person is describing experiments that would not have been possible without the help of a third party, perhaps in the provision of a crucial piece of information, an author will tend to beat endlessly about the bush, seeking to make clear to interested readers that his colleague's help had indeed been crucial without at the same time giving readers the impression that his own contribution had been unimportant.

It would be an interesting exercise to see what would happen to the unfolding content of the literature if journals were to follow the policy of publishing only clearly understandable articles. Would that be at once a guarantee of quality and an assurance that authors have nothing to hide?

In reality, this journal offers would-be Conrads opportunities too often declined. There is no set format, but a general understanding that articles will begin with a statement of a problem and a recitation of its antecedents, historical and otherwise, that it will continue with an account of what has been done and that it will end with some discussion of what has emerged - a conclusion ("Water flows uphill"), a qualified conclusion ("Water flows uphill only when the hill is spun rapidly in a centriguge") or an allusive suggestion that others may find helpful ("It has not escaped our attention that the phenomenon we describe may be relevant to the provision of public water supplies on the surfaces of rotating neutron stars"). As it should, the recipe has a beginning, a middle and an end. Conrad would have approved. When there is so much exciting discovery in all fields of science, it seems a shame that so much of it should be buried because the recipe is not followed.

John Maddox 